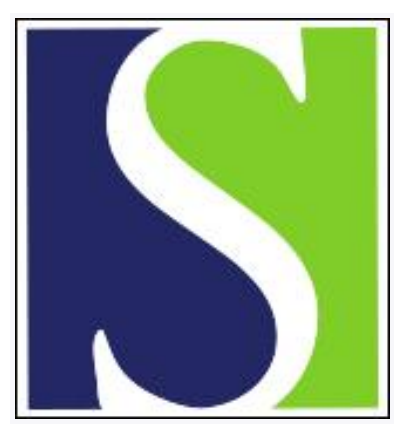

Scand J Work Environ Health 1989;15(2):136-141

https://doi.org/10.5271/sjweh.1871

Issue date: Apr 1989

Cytogenetic and hematological effects in plastics workers exposed to styrene.

by Hagmar L, Hogstedt B, Welinder H, Karlsson A, Rassner F

Affiliation: Department of Occupational Medicine, University Hospital, Sweden.

This article in PubMed: www.ncbi.nlm.nih.gov/pubmed/2772576

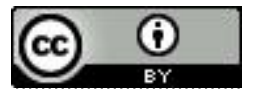




\title{
Cytogenetic and hematological effects in plastics workers exposed to styrene
}

\author{
by Lars Hagmar, MD, ${ }^{1}$ Benkt Högstedt, MD, ${ }^{2}$ Hans Welinder, MSc, ${ }^{1}$ Anita Karlsson, ${ }^{2}$ \\ Fredrik Rassner ${ }^{3}$
}

\begin{abstract}
HAGMAR L, HÖGSTEDT B, WELINDER H, KARLSSON A, RASSNER F. Cytogenetic and hematological effects in plastics workers exposed to styrene. Scand $J$ Work Environ Health 1989;15:136-41. For 20 glass-reinforced plastics workers exposed to styrene and 22 unexposed referents, the frequency and size distribution of micronuclei were determined for lymphocytes stimulated with phytohemagglutinin or pokeweed mitogen, and white blood cell counts were made. Furthermore, chromosome aberrations were scored for 11 of the exposed subjects and 15 of the referents. The mean level of styrene in the breathing zone of the workers was $56 \mathrm{mg} / \mathrm{m}^{3}$. Workers exposed to styrene did not show an increase in any of the cytogenetic end points studied when the effect of age and smoking was allowed for in a multiple regression analysis. A significant $30 \%$ increase in the number of peripheral monocytes was observed for the exposed workers. No correlations between the cytogenetic and hematological tests on one hand and the length of exposure time on the other could be detected.
\end{abstract}

Key terms: blood lymphocytes, chromosome aberrations, micronuclei, monocytes.

The organic solvent styrene (CAS number 100-42-5) is used mainly in the production of reinforced plastics, resins, and synthetic rubbers. Styrene has mutagenic properties, probably through its main reactive metabolite, styrene-7,8-oxide (1). Increased levels of chromosome aberrations (2-8), sister chromatid exchanges $(6,7)$, and micronuclei $(2,9,10)$ have been found in cultured lymphocytes from styrene-exposed workers. However, in other studies, no cytogenetic effects were found $(11,12)$.

During the last few years we have been able to develop the micronucleus assay for lymphocytes by preserving the cytoplasm of the cells (13), which increases the precision in scoring micronuclei, and by measuring micronucleus sizes, thus separating different inducing agents $(14,15)$. Furthermore, we have been using both phytohemagglutinin (PHA) and pokeweed (PWM) as mitogens which probably stimulate different subgroups of lymphocytes $(15,16)$.

The carcinogenic organic solvent benzene induces cytogenetic effects in humans and may also, due to a toxic depression of the bone marrow, cause lymphopenia in peripheral blood (17). In contrast, exposure to other organic solvents may cause lymphocytosis $(18,19)$. Whether styrene exposure may affect the peripheral lymphocyte level is not known. Thus differential white blood cell counts were included in the examination.

\footnotetext{
1 Department of Occupational Medicine, University Hospital, Sweden.

2 Department of Occupational Medicine, Central Hospital, Halmstad, Sweden.

3 Hälsoklippan AB, Klippan, Sweden.
}

Reprints requests to: Dr L Hagmar, Department of Occupational Medicine, University Hospital, S-221 85 Lund, Sweden.
The objectives of the present study were to investigate whether low-level exposure to styrene causes cytogenetic effects or disturbances in the peripheral white blood cell counts. Furthermore, we attempted to investigate whether styrene preferably induces larger micronuclei and whether the type of mitogen used, PHA or PWM, is of importance for styrene-induced micronuclei frequencies and size ratios.

\section{Subjects and methods}

\section{Production and exposure classification}

The exposed workers of the study came from a plant producing tanks of glass-reinforced polyester plastics. The framework of the tanks consists of cylindric tubes (diameter $600-2500 \mathrm{~mm}$ ) produced in a winding machine. Gables, tube flares, and other additional parts of the tanks are made by the spraying of glass and polyester compounds onto molds. Finally, the tanks are put together in an assembly hall. This part of the work includes hand-operated application of polyester. The polyester is dissolved in styrene, which has the double function of being a solvent and a reactive monomer. A peroxide initiates the polymerization reaction.

All the workers in the plant are exposed to styrene. In addition there is low-level exposure to acetone and methylene chloride, both of which are used for the cleaning of tools and skin.

The workroom air concentrations of styrene have been determined by personal sampling since 1974 . Results from a total sampling time of $703 \mathrm{~h}$ are given in table 1. The mean sampling time per sample was $60 \mathrm{~h}$. The mean concentration during the period 19851986 was $56 \mathrm{mg} / \mathrm{m}^{3}$. As the differences in the exposure 
levels between the different kinds of work have been small and there is a large rotation of work tasks among the workers, we have not tried to classify different work operations with regard to exposure levels.

Respiratory protection devices were used during spraying operations and during work with the polyester inside the tank, otherwise not.

For 43 urine samples collected immediately after work in October 1985, the mean excretion of the styrene metabolites mandelic acid and phenylglyoxylic acid was 128 (range $<6-317$ ) $\mathrm{mmol} / \mathrm{mol}$ creatinine.

\section{Subjects and sampling}

All 18 process operators and two foremen in the glassreinforced plastics plant, employed for at least one month, participated in the study. All but one were males. Their mean age was 40.5 (range 18-64) years, and their mean time of employment was 8.1 (range $0.1-25.4$ ) years.

Twenty-two male workers from a factory producing gelatin, without any significant chemical exposure, served as a reference group. Their mean age was 42.3 (range 23-61) years. The referents were not exposed to any industrial air pollutants. They were mainly working with internal transport, as electricians, technicians, and process supervisors.

All the subjects were interviewed by a physician (LH) with regard to occupational and medical history, especially concerning smoking habits (cigarettes per day; $1 \mathrm{~g}$ of pipe tobacco being considered equivalent to one cigarette), viral infections, drug intake, radiographic examinations, and exposure to ionizing radiation during the last year.

None of the referents had been occupationally exposed to styrene or any other solvents. Six out of 20 exposed workers were smokers, with a mean consumption of eight (range 3-13) cigarettes per day. Eleven out of 22 referents were smokers, with a mean consumption of 12 (range 2-20) cigarettes per day. Of the exposed subjects 13 had had radiographic examinations during the last year, and three regularly took drugs (theophyllin, terbutalin, pidolol, insulin). Two of the referents had had influenza during the last year,
12 had been examined radiographically, and five had a regular drug intake (glibencamid, digoxin, metoprolol, clonidin, alprenolol, prazosin).

\section{Methods}

Venous blood sampling. Venous blood samples were obtained from all the examined subjects between 0800 and 0900 on Monday mornings. Samples from all the subjects could not be cultured simultaneously. Thus the samples were taken on three consecutive Monday mornings. At each sampling time about half of the subjects were referents. All blood samples were coded and immediately transferred to the laboratory for analysis.

Micronucleus assay. Buffy coat leukocytes were cultured for $80 \mathrm{~h}$ in Roswell Park Memorial Institute (RPMI) 1640 medium with $15 \%$ fetal calf serum (Flow), as described by Högstedt (13). Parallel cultures were set up with either PHA (Gibco; $1 \mathrm{ml} / 100 \mathrm{ml}$ ) or PWM (Gibco; $1 \mathrm{ml} / 100 \mathrm{ml}$ ). It has earlier been shown that the appropriate incubation time is the same for both mitogens (15). The cells were prepared according to the method described by Högstedt (13).

In the first step 1000 lymphocytes from each individual were analyzed for the presence of intracellular micronuclei. In the second step, a number of cells corresponding to 10 micronuclei were scored, and the size of the cell nuclei and the micronuclei was measured according to the method described by Högstedt \& Karlsson (14). The size of the micronucleus was expressed as the ratio between the surface of the micronucleus and the corresponding main nucleus of the cell. This procedure has been found necessary as the different phases of the cell cycle cause different sizes of both cell nuclei and micronuclei. In no case was more than 3000 lymphocytes scored in the second step. We calculated the estimated frequency of micronuclei by adding the denominators and nominators, respectively, from both steps of the analysis. All scoring was performed by one observer. The interobservational precision of scoring micronuclei was very high; the correlation coefficient for the two steps of

Table 1. Levels of styrene, acetone, and methylene chloride in the workroom air measured by personal sampling during different years.

\begin{tabular}{|c|c|c|c|c|c|c|c|c|}
\hline \multirow{2}{*}{ Year(s) } & \multirow{2}{*}{$\begin{array}{l}\text { Samples } \\
\text { (N) }\end{array}$} & \multirow{2}{*}{$\begin{array}{l}\text { Total sampling } \\
\text { time }(\mathrm{h})\end{array}$} & \multicolumn{2}{|c|}{ Styrene $^{a}\left(\mathrm{mg} / \mathrm{m}^{3}\right)$} & \multicolumn{2}{|c|}{ Acetone ${ }^{b}\left(\mathrm{mg} / \mathrm{m}^{3}\right)$} & \multicolumn{2}{|c|}{$\begin{array}{l}\text { Methylene chloride } \\
\left(\mathrm{mg} / \mathrm{m}^{3}\right)\end{array}$} \\
\hline & & & Mean & Range & Mean & Range & Mean & Range \\
\hline 1974 & 30 & 140 & 221 & $52-551$ & $\cdots$ & $\cdots$ & $\cdots$ & $\cdots$ \\
\hline 1976 & 9 & 49 & 43 & $14-90$ & $\cdots$ & . & $\cdots$ & $\cdots$ \\
\hline $1980-1981$ & 11 & 71 & 76 & $20-134$ & $\cdots$ & . & $\cdots$ & $\cdots$ \\
\hline $1983-1984$ & 7 & 49 & 115 & $88-120$ & $\cdots$ & $\cdots$ & $\cdots$ & . \\
\hline 1985 & 33 & 245 & 49 & $4-145$ & 41 & $17-120$ & 12 & $1-35$ \\
\hline 1986 & 28 & 149 & 68 & $18-164$ & 45 & $15-137$ & 14 & $0-48$ \\
\hline
\end{tabular}

a Swedish occupational exposure limit $=110 \mathrm{mg} / \mathrm{m}^{3}$.

b Swedish occupational exposure limit $=600 \mathrm{mg} / \mathrm{m}^{3}$.

c Swedish occupational exposure limit $=250 \mathrm{mg} / \mathrm{m}^{3}$. 
the analysis was 0.98 for PHA-induced lymphocytes and 0.96 for $\mathrm{PWM}$-induced lymphocytes $(\mathrm{P}<0.001$ in both cases, Spearman's rank order correlation coefficient).

Chromosome aberrations in lymphocytes. Ten drops of whole blood were incubated at $37^{\circ} \mathrm{C}$ with PHA in $10 \mathrm{ml}$ of medium containing RPMI 1640 and $15 \%$ fetal calf serum. The incubation time was $48 \mathrm{~h}$. Colcemid $(0.1 \mu \mathrm{g} / \mathrm{ml})$ was added $1 \mathrm{~h}$ before the harvest. Hypotonic treatment was carried out with potassium chloride $(0.075 \mathrm{~mol} / \mathrm{l})$ for $15 \mathrm{~min}$ at room temperature, and the cells were fixed in methanol/acetic acid (3:1). The chromosome preparations were stained with Giemsa. For each individual, 100 metaphases were scored according to the classification system recommended by the International System for Human Cytogenetic Nomenclature (20). The results have been presented as "gaps" and "breaks" (comprising chromatid and isochromatid breaks, pericentric inversions, rings, and dicentrics).

Due to poor preparations and mitotic inhibition, slides from nine exposed subjects and seven referents were not scored. Five of the 11 exposed subjects examined and nine of the 14 examined referents were smokers.

Differential white blood cell counts. In each blood sample 10000 cells were analyzed by a Technicon $\mathrm{H}-6000 \mathrm{C}^{(\mathrm{p})}$ automated flow cytochemistry cell counter (21). The precision for this technique is very good, as shown in a previous study (22).

Statistical methods. For intraindividual comparisons of the frequencies and size ratios of micronuclei, between PHA and PWM cultures, Wilcoxon matchedpairs signed-rank test and the Pearson correlation coefficient were used. For interobservational variation of the micronuclei scoring, Spearman's rank order correlation coefficient was calculated.

The styrene-exposed group and the referents were compared with regard to the biological effect variables, age and smoking habits being allowed for in the multiple regression analysis. Furthermore, in a multiple regression analysis of the biological effect variables performed only for the styrene-exposed group, the importance of employment time in the plant was tested with age and smoking being allowed for.

As the frequencies of chromosome aberrations (range $0-5 / 100$ cells) were very low, the average square root transformation $[(\sqrt{\mathrm{x}}+\sqrt{\mathrm{x}}+1) / 2]$ was applied to these counts in order to stabilize the variance (23). Graphic methods showed that the log-transformation was suitable for both the frequencies of micronuclei and the white blood cell counts. The individual geometric mean values of the size ratios for micronuclei were analyzed untransformed.

Significance levels of $5 \%$ or less have been considered significant. All the statistical tests were two-tailed.

\section{Results}

With PWM stimulation the mean frequency of micronuclei, for all the examined subjects, was 6.5 $\%$, compared to $4.4 \%$ with PHA. This difference was statistically significant $(\mathrm{P}<0.0001$; Wilcoxon matched-pairs signed-rank test). The correlation coefficient between the two log-transformed scores was 0.37 (Pearson's $\mathrm{r}, \mathrm{P}=0.02$ ).

For lymphocytes stimulated with either PHA or PWM, no statistically significant difference was found in the frequencies of micronuclei between the exposed and reference groups when allowance was made for age and smoking (table 2). For the cultures stimulated with PHA, but not for those stimulated with PWM, the micronucleus frequencies showed a significant positive association with age $(P<0.0001)$. No association with smoking habits was found.

There was no significant difference in the individual mean micronucleus size ratios between the lymphocytes stimulated with PHA or PWM ( $P=0.29$ Wilcoxon matched-pairs signed-rank test). Furthermore, there was no correlation between the two scores (Pearson's $r=0.15, P=0.4$ ).

The individual mean micronucleus size ratios were not associated with exposure to styrene, irrespective of the mitogen used (table 2). For the cultures stimulated with PHA, but not for those stimulated with PWM, the size ratios showed a significant association with age $(\mathrm{P}=0.004)$. No association with smoking habits was found.

Furthermore, no association between either the micronucleus frequencies or the size ratios and the length of employment was found for the exposed group.

There was no statistically significant difference for chromosome breaks between the exposed and reference groups when allowance was made for age and smoking (table 3 ). On the other hand, significantly $(\mathrm{P}=0.02)$ more gaps were observed for the referents. No association between either the chromosome breaks or gaps and the length of employment was found for the exposed group.

The number of peripheral monocytes, but not that of any other leukocytes, was increased in the exposed group when it was compared with the reference group (table 4). The mean difference was $30 \%$ and statistically significant $(P=0.002)$. No association between any leukocyte count and length of employment was found for the exposed group.

\section{Discussion}

The main result of this study was that workers exposed to styrene did not show an increase in micronucleus frequencies or size ratios, irrespective of whether PHA or PWM was used as the mitogen, or chromosome aberrations. 
Table 2. Mean number of micronuclei and the individual mean values of the size ratios for micronuclei in lymphocytes stimulated with phytohemagglutinin (PHA) or pokeweed (PWM) in 20 styrene-exposed workers and 22 referents. The unadjusted $95 \%$ confidence interval $(95 \% \mathrm{Cl})$ is also given. The significance level for the numbers of micronuclei refers to the difference in the means after log-transformation and for the untransformed individual mean size ratios, in both cases adjusted for age and smoking.

\begin{tabular}{|c|c|c|c|c|c|c|c|}
\hline \multirow{2}{*}{ Micronuclei } & \multicolumn{2}{|c|}{ Styrene-exposed } & \multicolumn{2}{|c|}{ Referents } & \multirow{2}{*}{$\mathrm{P}$} & \multicolumn{2}{|c|}{ Covariates (P-value) } \\
\hline & Mean & $95 \% \mathrm{Cl}$ & Mean & $95 \% \mathrm{Cl}$ & & Age & Smoking \\
\hline \multicolumn{8}{|l|}{ PHA } \\
\hline $\begin{array}{l}\text { Frequency }(\% 0) \\
\text { Size ratio }\end{array}$ & $\begin{array}{l}4.3 \\
0.023\end{array}$ & $\begin{array}{c}3.5-5.4 \\
0.019-0.026\end{array}$ & $\begin{array}{l}4.4 \\
0.023\end{array}$ & $\begin{array}{c}3.5-5.6 \\
0.020-0.027\end{array}$ & $\begin{array}{l}>0.5 \\
>0.5\end{array}$ & $\begin{array}{c}<0.0001 \\
0.004\end{array}$ & $\begin{array}{l}0.4 \\
0.4\end{array}$ \\
\hline \multicolumn{8}{|l|}{ PWM } \\
\hline $\begin{array}{l}\text { Frequency }(\% 00) \\
\text { Size ratio }\end{array}$ & $\begin{array}{l}5.9 \\
0.020\end{array}$ & $\begin{array}{c}5.0-6.9 \\
0.018-0.023\end{array}$ & $\begin{array}{l}7.0 \\
0.022\end{array}$ & $\begin{array}{c}6.1-8.1 \\
0.020-0.025\end{array}$ & $\begin{array}{l}0.07 \\
0.19\end{array}$ & $\begin{array}{r}0.4 \\
>0.5\end{array}$ & $\begin{array}{l}>0.5 \\
>0.5\end{array}$ \\
\hline
\end{tabular}

Due to technical problems, the scoring of chromosome aberrations was performed for only 26 of the 42 subjects. The loss was not systematic with respect to the exposed subjects and referents and thus did not introduce any bias.

In the present study the referents had significantly more gaps than the exposed workers. However, all the scores were low and within the "normal" limits of the laboratory. As the referents were not chemically exposed, the discrepancy in the number of gaps was considered a spurious finding.

The mean exposure levels of styrene in the air were considerably higher $\left(477\right.$ and $197 \mathrm{mg} / \mathrm{m}^{3}$ in some of the previous "positive" studies $(4,6)$ in comparison with the exposure level of $56 \mathrm{mg} / \mathrm{m}^{3}$ of the present study. However, an increased number of chromosome aberrations $(8)$ and micronuclei $(9,10)$ has been observed also for workers exposed to styrene levels in the same range $\left(55,55\right.$, and $\left.101 \mathrm{mg} / \mathrm{m}^{3}\right)$ as that of the present study. On the other hand, Mäki-Paakkanen (12) could not show an increase in chromosome aberrations, sister chromatid exchanges, or micronuclei in workers exposed to a mean level of $98 \mathrm{mg} / \mathrm{m}^{3}$ styrene. Thus no consistent dose-response relationship between styrene exposure level and cytogenetic end points have been demonstrated so far. Furthermore, no association between cytogenetic effects and length of exposure time has been found (12). This inability to demonstrate dose-response relationships may depend on the low precision of cytogenetic methods or the problem of identifying the relevant exposure parameter. The mean level of exposure is a very insensitive parameter. High occasional exposure peaks, which probably vary in both amplitude and frequency between different plants, may be of greater importance for cytogenetic effects than the time-weighted average level. In addition the age distribution of lymphocytes in peripheral blood may differ between subjects. Thus a blood sample with many young lymphocytes probably reflects a more recent exposure than a sample with many older lymphocytes. The relevant exposure parameter may therefore vary between different exposed subjects, and this possibility contributes to the difficulties in displaying dose-response relationships.
Table 3. Mean number of gaps and chromosome breaks in 11 styrene-exposed workers and 14 referents. The standard deviation (SD) and range are also given. The significance level refers to the difference in the means after average square root $[(\sqrt{ } x+\sqrt{ } x+1) / 2]$ transformation, adjusted for age and smoking.

\begin{tabular}{|c|c|c|c|c|c|}
\hline \multirow{2}{*}{$\begin{array}{l}\text { Chromosome } \\
\text { aberration }\end{array}$} & \multicolumn{2}{|c|}{ Styrene-exposed } & \multicolumn{2}{|c|}{ Referents } & \\
\hline & Mean SD & Range & Mean SD & Range & \\
\hline $\begin{array}{l}\text { aps } 1 \% \\
\text { reaks }\end{array}$ & $\begin{array}{ll}0.7 & 1.2 \\
1.2 & 1.6\end{array}$ & $\begin{array}{l}0-3 \\
0-5\end{array}$ & $\begin{array}{ll}1.7 & 1.4 \\
1.5 & 2.1\end{array}$ & $\begin{array}{l}0-5 \\
0-5\end{array}$ & $\begin{array}{l}0.02 \\
0.5\end{array}$ \\
\hline
\end{tabular}

Table 4. Geometric mean differential counts of the white blood cells, and unadjusted $95 \%$ confidence interval $(95 \% \mathrm{Cl})$, for 20 styrene-exposed workers and 22 referents. The P-value refers to the difference in the means adjusted for age and smoking habits. The calculations were based on log-transformed dependent variables.

\begin{tabular}{|c|c|c|c|c|c|}
\hline \multirow{2}{*}{ Leukocytes } & \multicolumn{2}{|c|}{ Styrene-exposed } & \multicolumn{2}{|c|}{ Referents } & \multirow{2}{*}{$P$} \\
\hline & Mean & $95 \% \mathrm{Cl}$ & Mean & $95 \% \mathrm{Cl}$ & \\
\hline Neutrophils $(109 / 1)$ & 3.94 & $3.23-4.81$ & 4.13 & $3.40-5.02$ & 0.3 \\
\hline Eosinophils (109/1) & 0.18 & $0.14-0.23$ & 0.14 & $0.11-0.17$ & 0.17 \\
\hline Basophils (109/1) & 0.06 & $0.05-0.08$ & 0.06 & $0.04-0.07$ & 0.4 \\
\hline Monocytes (109/I) & 0.47 & $0.40-0.55$ & 0.36 & $0.31-0.41$ & 0.002 \\
\hline Lymphocytes $\left(10^{9} / 1\right)$ & 2.17 & $1.93-2.45$ & 2.04 & $1.72-2.41$ & 0.4 \\
\hline $\begin{array}{l}\text { "Large unstained } \\
\text { cells" }\left(10^{9} /\right)\end{array}$ & 0.08 & $0.06-0.10$ & 0.07 & $0.06-0.09$ & 0.3 \\
\hline
\end{tabular}

It has previously been shown in vitro that the size distribution of micronuclei depends on the type of inducing agent $(14,24)$. In an in vivo study of piperazineexposed workers we have also observed a different size distribution between the exposed and reference groups (15). However, no such difference could be found in the present study of styrene-exposed workers.

It is well established that there is an association between age and the frequency of micronuclei in PHAactivated lymphocytes $(13,15,22)$. As in the previous study of piperazine-exposed workers, there was also an age effect on the size distribution in the present study. Thus it is apparent that not only the numbers of micronuclei, but also the sizes increase with age. 
This age effect on size may depend on the increased lagging of sex-linked chromosomes by age (25).

The frequencies of micronuclei induced in vitro by $\mathrm{X}$-rays and mitomycin $\mathrm{C}$ in lymphocytes activated with PWM were found to be significantly higher than in PHA cultures (16). This was also the case in the in vivo study of piperazine-exposed workers (15). We have suggested that the two mitogens activate lymphocyte subgroups of different sensitivity to mutagens. Such an effect was, however, not observed for the styreneexposed workers.

Regardless of exposure the micronucleus frequencies in the PWM-cultured lymphocytes were significantly higher than in the PHA-activated cells. This difference cannot be attributed to a difference in variance (table 2). Therefore, it is likely that also the "normal" level of micronuclei is higher with PWM than with PHA.

It is well known that exposure to benzene may cause lymphopenia (17). On the other hand, workers exposed to other solvents have shown peripheral lymphocytosis $(18,19)$. In addition workers exposed to various chemicals, including organic solvents, in a chemical plant showed lymphocytosis, and also increased levels of eosinophils and basophils but not monocytes (22). The present study does not indicate that low-level exposure to styrene affects the lymphocyte cell count. It is not obvious whether the observed, marginal increase in monocytes is a spurious finding or reflects the styrene exposure. However, it should be emphasized that using the automated cytochemistry counting technique makes it possible to detect much smaller differences in the cell counts than older techniques allowed. The intraassay variation for monocyte counts has been shown to be less than $4 \%$ (22).

It could be questioned whether or not an extended analysis of the leukocytes ought to be performed in all cytogenetic studies, including measuring the subgroups of lymphocytes before starting the cultures. The rationale for this procedure is that not only the type of mitogen may alter the composition of lymphocytes studied, but also different types of chemical exposures may have this effect in vivo. It is interesting to note that we not only found an excess of micronuclei in a piperazine-exposed group of workers, but also an increased number of lymphocytes (15). Furthermore, in a recent study of gasoline pump repair workers, we obtained the same results (Högstedt, unpublished results). It could not be ruled out that positive cytogenetic findings could be attributed to differences in the composition of the lymphocyte subgroups studied. Moreover, the exposure-related differences in the peripheral leukocyte cell counts do not necessarily reflect increases in the production of leukocytes. They may rather be the result of an altered distribution of white blood cells between different compartments of the body.

\section{Acknowledgments}

The project was supported by generous grants from the Swedish Work Environment Fund, The Swedish Cancer Society, and the Ellen, Walter, and Lennart Hesselman's Foundation for Scientific Research.

The excellent technical assistance of Ms A Andreasson and Ms C Gustavsson is gratefully acknowledged. Ms A Nilsson and Ms E Nilsson are acknowledged for their collection of the blood samples.

\section{References}

1. Vainio H, Norppa H, Beldevere G. Metabolism and mutagenicity of styrene and styrene oxide. In: Järvisalo J, Pfäffli P, Vainio H, ed. Industrial hazards of plastic and synthetic elastomers. New York, New York: Liss, 1984:215-25.

2. Meretoja T, Vainio H, Sorsa M, Härkönen H. Occupational styrene exposure and chromosomal aberrations. Mutation Res 1977;56:193-7.

3. Meretoja T, Järventaus H, Sorsa M, Vainio H. Chro. mosome aberrations in lymphocytes of workers exposed to styrene. Scand J Work Environ Health 1978;4(suppl 2):259-64.

4. Fleig I, Thiess AM. Mutagenicity study of workers employed in the styrene and polystyrene processing and manufacturing industry. Scand J Work Environ Health 1978;4(suppl 2):254-8.

5. Högstedt B, Hedner K, Mark-Vendel E, Mitelman F, Schütz A, Skerfving S.Increased frequency of chromosome aberrations in workers exposed to styrene. Scand J Work Environ Health 1979;5:333-5.

6. Andersson HC, Tranberg EÄ, Uggla AH, Zetterberg G. Chromosomal aberrations and sister-chromatid exchanges in lymphocytes of men occupationally exposed to styrene in a plastic-boat factory. Mutat Res 1980; $73 ; 387-401$.

7. Camurri L, Codeluppi S, Pedroni C, Scarduelli L. Chromosomal aberrations and sister-chromatid exchanges in workers exposed to styrene. Mutat Res 1983;119:361-9.

8. Hansteen I-L, Jelmert Ø, Torgrimsen T, Førsund B. Low human exposure to styrene in relation to chromosome breaks, gaps and sister chromatid exchanges. Hereditas 1984;100:87-91.

9. Högstedt B, Ảkesson B, Axell K, et al. Increased frequency of lymphocyte micronuclei in workers producing reinforced polyester resin with low exposure to styrene. Scand J Work Environ Health 1983;9:241-6.

10. Nordenson I, Beckman L. Chromosomal aberrations in lymphocytes of workers exposed to low levels of styrene. Hum Hered 1984;34:178-82.

11. Watanabe T, Endo A, Kumai M, Ikeda M. Chromosome aberrations and sister chromatid exchanges in styrene-exposed workers with reference to their smoking habits. Environ Mutagen 1985;5:299-309.

12. Mäki-Paakkanen J. Chromosome aberrations, micronuclei and sister-chromatid exchanges in blood lymphocytes after occupational exposure to low levels of styrene. Mutat Res 1987;189:399-406.

13. Högstedt B. Micronuclei in lymphocytes with preserved cytoplasm - a method for assessment of cytogenetic damage in man. Mutat Res 1984;130:63-72.

14. Högstedt $\mathbf{B}$, Karlsson $\mathrm{A}$. The size of micronuclei in human lymphocytes varies according to inducing agent used. Mutat Res 1985;156:229-32.

15. Högstedt B, Bratt I, Holmén A, Hagmar L, Skerfving $\mathrm{S}$. Frequency and size distribution of micronuclei in lymphocytes stimulated with phytohaemagglutinin and pokeweed mitogen in workers exposed to piperazine. Hered- 
itas 1988;109:139-42.

16. Högstedt B, Karlsson A, Holmén A. Frequencies of micronuclei in human peripheral blood lymphocytes stimulated in vitro by phytohemagglutinin and pokeweed mitogen. Hereditas 1988;109:53-5.

17. Goldstein BD. Biological and ambient monitoring of benzene in the workplace. J Occup Med 1986;28: $1051-4$.

18. Angerer J, Wulf $\mathrm{H}$. Occupational chronic exposure to organic solvents: XI. alkylbenzene exposure of varnish workers: effects on hematopoetic system. Int Arch Occup Environ Health 1985;56:307-21.

19. Denkhaus W, v Steldern D, Botzenhardt V, Konietzko H. Lymphocyte subpopulations in solvent-exposed workers. Int Arch Occup Environ Health 1986;57: $109-15$.

20. International System for Human Cytogenetic Nomenclature. Birth defects. New York, New York: March of Dimes Birth Defects Foundation, 1985. (Original article series; vol 21, no 1.)
21. Mansberg HP, Saunders AM, Groner W. The Hema$\log \mathrm{D}$ white cell differential system. J Histochem Cytochem 1974;22:711-24.

22. Hagmar L, Bellander T, Högstedt B, et al. Biological effects in a chemical factory with mutagenic exposure: I. cytogenetic and haemtological parameters. Int Arch Environ Occup Health 1988;60:437-44.

23. Whorton EB. Some experimental design and analysis considerations for cytogenetic studies. Environ Mutagen 1985;7:9-15.

24. Yamamoto KI, Kikuchi Y. A comparison of diameters of micronuclei induced by clastogens and by spindle poisons. Mutat Res 1980;71:127-31.

25. Evans HPJ. What has been achieved with cytogenetic monitoring? In: Sorsa M, Norppa H, ed. Monitoring of occupational genotoxicants. New York, New York: Alan R Liss, Inc, 1986;3-23.

Received for publication: 6 October 1988 